\title{
Yetişkin yaşta akut üst gastrointestinal sistem kanaması ile prezente olan Henoch-Schönlein vasküliti, endoskopik bulguları: Olgu sunumu
}

\author{
Henoch-Schönlein vasculitis in an adult presenting with upper gastrointestinal bleeding - endoscopic \\ findings: A case report
}

\author{
Ahmet UYANIKOĞLU, Timuçin AYDOĞAN, Haşim NAR, Rıza ALTUNBAŞ, Necati YENICE \\ Harran Üniversitesi, Tip Fakültesi, Gastroenteroloji Bilim Dalı, Şanlıurfa
}

\begin{abstract}
Henoch -Schönlein purpurası çocuklarda en slk görülen vaskülit iken, erişkinde nadir görülen sistemik vaskülittir. Küçük damarları etkiler ve sıklıkla palpabl purpura ile prezente olur. Yetişkinde cilt tutulumu sonrası en fazla böbrek ve gastrointestinal tutulum olur. Gastrointestinal tutulumda slkllkla gastrointestinal kanama gözlenir fakat masif gastrointestinal kanama nadirdir. Karın ağrnsı şikayeti ile polikliniğimize başvuran ve yatışı sonrasında hemodinamiyi bozan masif üst gastrointestinal kanama görülen erişkin erkek olgu sunulmuştur.
\end{abstract}

Anahtar kelimeler: Henoch-Schönlein vaskülit, üst gastrointestinal kanama

\section{GİRISS}

Henoch-Schönlein purpurası (HSP) damar duvarında IgA depolanmasının izlendiği, deri bulgularının ön planda olduğu bir küçük damar vaskülitidir (1). Palpabl purpuraların yanı sıra karın ağrısı, artralji, hematüri, proteinüri gibi sistemik semptomlar da eşlik edebilir (2). Karın ağrısı en sık görülen semptomlardandır (3). HSP erişkinlerde daha nadiren görülür ve klinik prezentasyonu çocuklardan biraz farklıdır. Genellikle daha ciddi seyreder, diyare ve böbrek tutulumu daha sıktır, daha sık ciddi tedavi ve uzun hastane yatışı gerekir (4). Erişkin çağda nadir görülmesine rağmen karın ağrısı ve akut üst gastrointestinal sistem kanaması ile prezente olan 22 yaşında Henoch-Schönlein purpuralı erkek hasta sunulmuştur.

\section{OLGU}

Gastroenteroloji polikliniğine karın ağrısı ve gaitada siyahlaşma şikayeti ile müracat eden hastanın, fizik muayenesinde alt ekstremite ekstansör yüzlerde daha belirgin olan döküntü (Resim 1) ve epigastrik hassasiyet dışında özellik yoktu. Hasta üst gastrointestinal sistem kanaması ve vaskülit ön tanısı ile yatırıldı. Yatışının 1. gününde tetkiklerinde lökosit 8820/ $\mathrm{mm}^{3}$, hemoglobin 10,4 g/dl, trombosit 171.000 idi ve idrar tahlili ve biyokimyasal tetkiklerinde özellik yoktu. Protrombin zamanı 12 saniye HBsAg ve Anti HCV negatif saptandı. Gastroskopisinde antrumda ve duodenum 2. kisimda daha belirgin olmak üzere ödem, eritem, hemorajik kanama odakları ve multipl irregüler ülserler saptandı (Resim 2-4). Döküntüleri
While Henoch-Schönlein purpura is the most common acute systemic vasculitis in childhood, it is rare in adults. It affects small vessels and is the most common cause of palpable purpura. In adults, the gastrointestinal system and kidneys are the most common sites of involvement after the skin. Gastrointestinal bleeding is usually occult; massive gastrointestinal bleeding is rare. We report a case who admitted to our clinic with the complaint of abdominal pain who presented massive upper gastrointestinal bleeding and disrupted hemodynamics after hospitalization.

Key words: Henoch-Schönlein vasculitis, upper gastrointestinal bleeding.

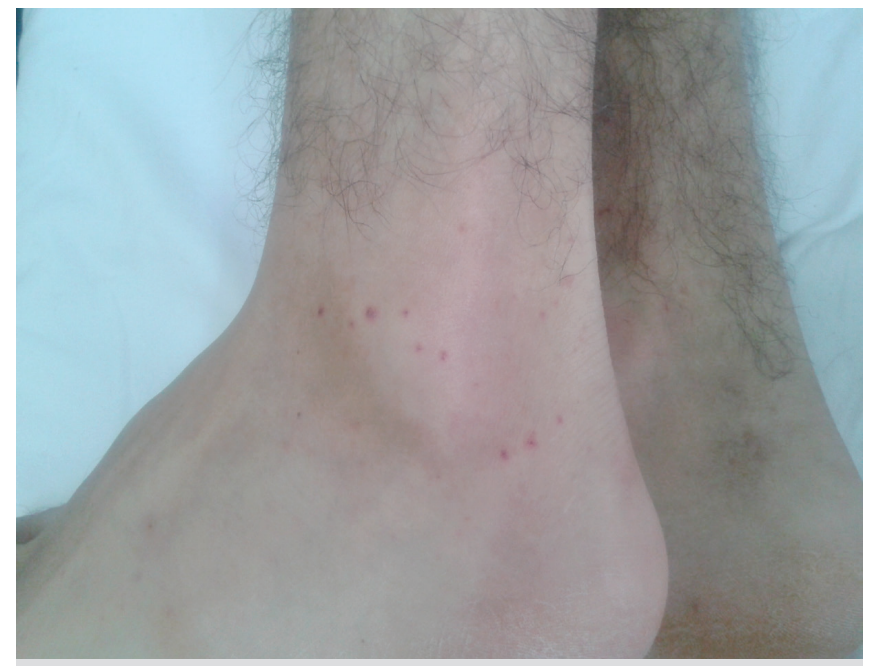

Resim 1. Alt ekstremitelerde peteşial döküntüler

nedeniyle dermatoloji konsültasyonu yapilarak cilt biyopsisi yapıldı. Takiplerinde melenası artan, hemodinamisi bozulan hasta yoğun bakım ünitesine alınarak parenteral sıvı, 6 ünite eritrosit süspansiyonu, proton pompa inhibitörü infüzyonu yapıldı. Cilt biyopsisi vaskülit ile uyumlu saptanan hastaya $1 \mathrm{mg} / \mathrm{kg}$ metil prednisolon başlandı. Yoğun bakım ünitesinde yatışının 4. gününde melenası ve hemodinamisi düzelen hasta servise alınd. Hasta romatoloji ve gastroenteroloji poliklinik takipleri önerilerek taburcu edildi. 


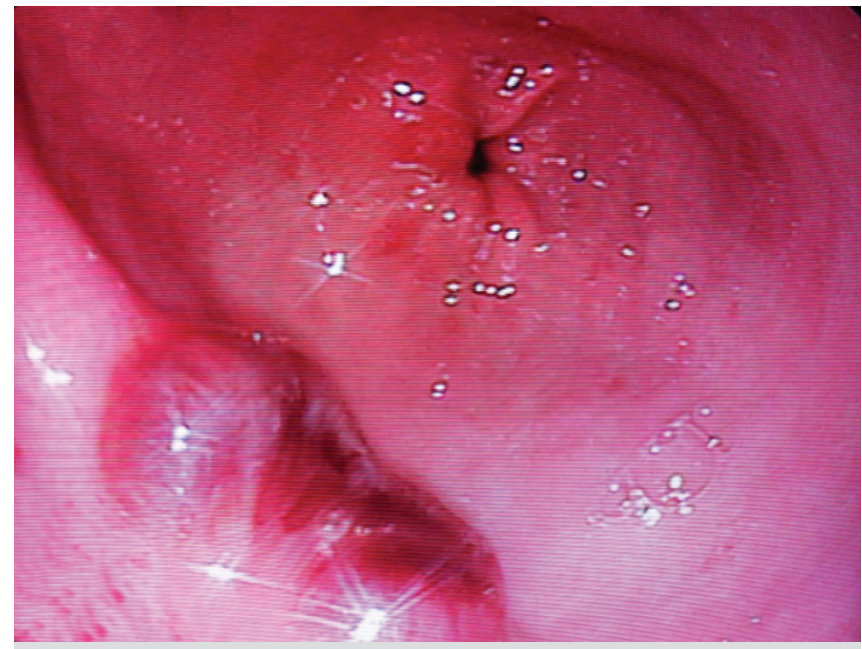

Resim 2. Antrum hiperemik, ödemli, hemorajik kanama odakları
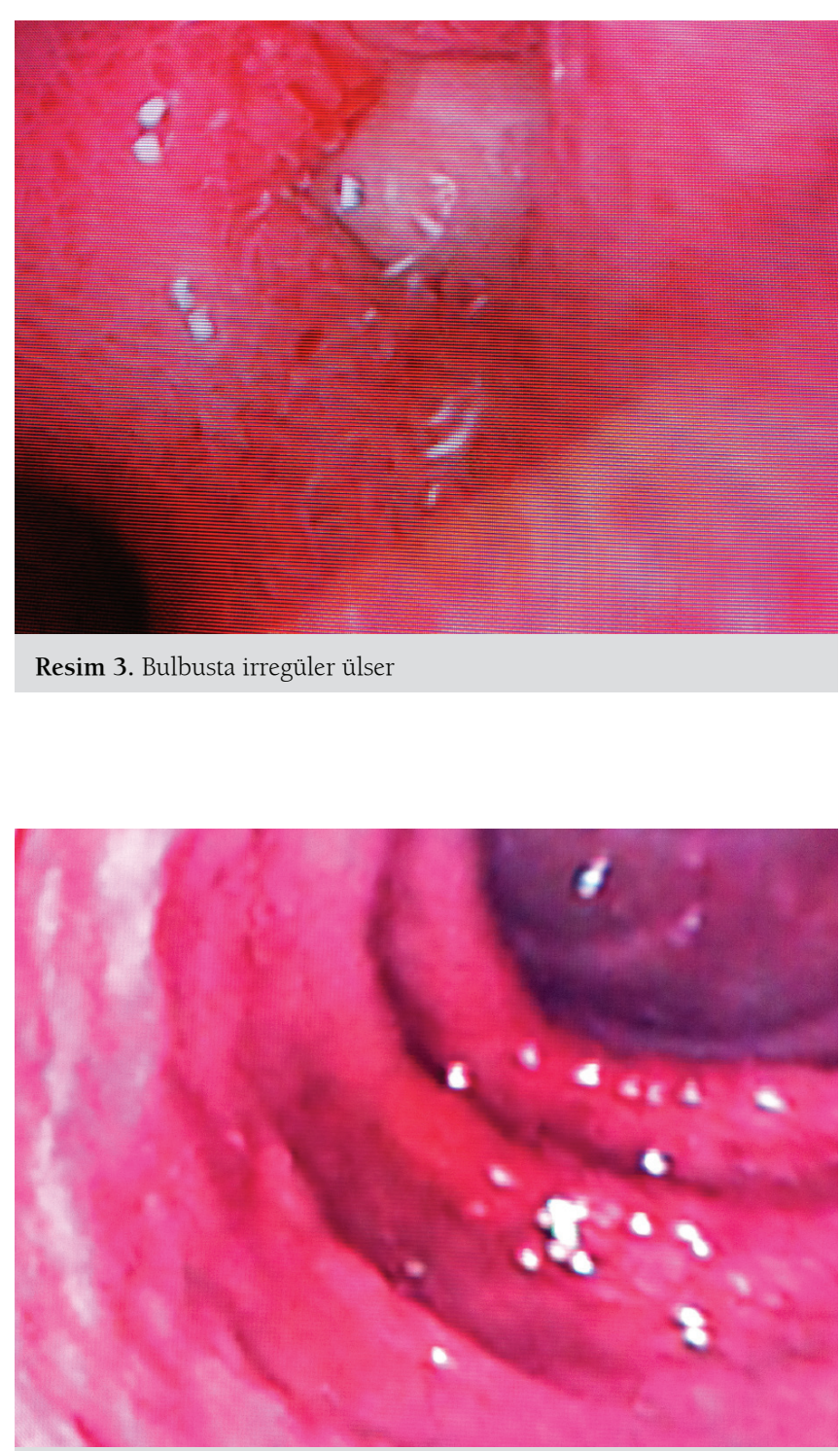

Resim 4. Duodenum 2.kısım ödemli, eritemli, hemorajik

\section{TARTIŞMA}

Henoch-Schönlein purpurası deride palpabl, nontrombositopenik purpura gelişimine yol açan, beraberinde gastrointestinal, eklem ve böbrek tutulumunun da eşlik edebildiği küçük damar vaskülitidir $(1,2,5)$. Gastrointestinal sistem HSP'nin deriden sonra en sık etkilediği ikinci tutulum bölgesidir. Kolik şeklinde karın ağrısı en sık görülen bulgudur. Erken çocukluk çağında gastrointestinal tutulum sıklığı erişkin dönemle karşılaştırıldığında daha az olarak bildirilmektedir. Pillebout ve arkadaşları, erişkin dönemde HSP'li olguların \%48'inde gastrointestinal sistem tutulumu saptamışlar ve kanama bu olguların \%5l'inde görülmüştür (6). Türkiyeden bildirilen bir seride HSP tanısı alan 16 erişkin olguda kadın erkek oranı 7/9 olup, yaş aralığı ortalaması 53,38 $\pm 14,43$ yıl olarak bulundu. Peteşi ve palpabl purpura tarzı lezyonlar en sık alt ekstremite olmak üzere (\%100), 10 (\%62,5) olguda üst ekstremiteler, 7 (\%43,8) olguda gövdede lokalizeydi. Eklem tutulumu 4 (\%25) olguda, gastrointestinal sistem tutulumu $5(\% 31,3)$ olguda mevcuttu (7). Bizim olgumuz erkek, genç hasta, alt ekstremitede çok belirgin olmayan döküntüleri vardı, ön planda karın ağrısı ve akut üst gastrointestinal kanaması ile prezente olmuştu.

Eklem tutulumu çocukluk çağında HSP'nin sık görülen bulgularından biridir. Genellikle diz, ayak bileği gibi büyük eklemlerde artrit şeklinde klinik verir ve deformite birakmadan iyileşme gösterir. Yaş ilerledikçe eklem tutulumu sıklığının giderek azalma gösterdiği bildirilmektedir. Erişkinlerde renal tutulum daha şiddetlidir, gastrointestinal tutulum daha hafif, aynı şiddette veya daha şiddetli olabilir $(1,8,9)$. Hastamızda eklem ve böbrek tutulumu saptanmadı. Gastrointestinal tutulum şiddetli idi.

Gastrointestinal tutulumda endoskopide mukozal eritem, ödem, multipl irregüler ülserler, nodüler değişiklikler görülür. Üst gastrointestinal sistemde duodenum 2.kısmı en sık tutulan ve en ciddi lezyonların görüldüğü kısımdır. Alt gastrointestinal sistemde ise en sik rektum tutulur, ancak en ciddi tutulum terminal ileumda olur. HSP tipik deri lezyonları olmadan akut batın tablosu ile müracaat edebilir ve gastroskopi, kolonoskopi erken tanı için faydalıdır. Özellikle duodenum 2.kısım ve terminal ileumda görülen diffüz mukozal ödem, eritem, peteşi veya multipl irregüler ülserler tipik endoskopik bulgulardır $(9,10,12)$. Bizim olgumuzda da döküntüler çok belirgin olmamasına rağmen gastroskopide tipik bulgular (Resim 2-4) saptandi.

Sistemik steroid tedavisi böbrek tutulumu veya şiddetli ekstrarenal semptomlarda endikedir. Oral prednizon genellikle 1-2 $\mathrm{mg} / \mathrm{kg} /$ gün arası dozlarda orta şiddetliden ağır semptomlara yol açabilen gastrointestinal sistem ve eklem tutulumunda ve HSP'nin deri lezyonlarının progresyonunun durdurulmasında önerilmektedir (12). Kortikosteroid tedavisinin karın ağrısını ve kanamayı kontrol etmede yararlı olduğu bildirilmiştir (1315). Kortikosteroidlerin dişında diğer immünsüpresifler de kullanılmıştır $(3,16)$. Hastamızda deri biyopsisinin vaskülit ile uyumlu gelmesinin ardından proton pompa inhibitörüne $1 \mathrm{mg} / \mathrm{kg}$ metil prednisolon eklendi, hastanın karın ağrısı azal$\mathrm{d}$, tedavinin 4 . gününde hastanın melenası ve hemodinamisi düzeldi, kanama kontrol altına alınabildi. Bizim hastamızda 
da kortikosteroid tedavisi karın ağrısının azalmasında ve kanamanın kontrol altına alınmasında faydalı olmuştur.

Sonuç olarak Henoch-Schönlein vasküliti daha çok çocukluk çağında görülmekle birlikte ileri yaşta da ortaya çıkabil-

\section{KAYNAKLAR}

1. Başak M, Erden A, Bulut K, et al Gastrointestinal kanama ile bašvuran erişkin başlangıçlı Henoch-Schönlein vasküliti ve ankilozan spondilitli bir olgu (A case with adult-onset Henoch-Schönlein vasculitis presenting with gastrointestinal bleeding and ankylosing spondylitis). Endoscopy Gastrointestinal 2013;21:19-21.

2. Shin JI, Lee JS. Comment on: Clinical and histopathological features in Henoch-Schönlein purpura (Int J Dermatol 2008 January; 47(1):48-9.). Int J Dermatol 2008;47:1088.

3. Jinga M, Jurcut C, Vasilescu F, et al. A rare case of digestive hemorrhage in an elderly patient: diagnosis and treatment difficulties. Rom J Morphol Embryol 2012;53(3 Suppl):831-4.

4. Uppal SS, Hussain MA, Al-Raqum HA, et al. Henoch-Schönlein's purpura in adults versus children/adolescents: A comparative study. Clin Exp Rheumatol 2006;24(2 Suppl 41):S26-30.

5. Calvo-Río V, Loricera J, Martín L, et al. Henoch-Schönlein purpura nephritis and IgA nephropathy: a comparative clinical study. Clin Exp Rheumatol 2013;31(1 Suppl 75):S45-51.

6. Pillebout E, Thervet E, Hill G, et al. Henoch-Schönlein purpura in adults: outcome and prognostic factors. J Am Soc Nephrol 2002;13:1271-8.

7. Akay BN, Ünlü e, Şanlı H, Akyol A. Erişkinlerde Henoch-Schönlein purpurasının klinik özellikleri ve takip sonuçları (Henoch-Schönlein purpura in adults: clinical features and outcome). Asthma Allergy Immunol 2010;8:38-45.

8. García-Porrúa C, Calviño MC, Llorca J, et al. Henoch-Schönlein purpura in children and adults: clinical differences in a defined population. Semin Arthritis Rheum 2002;32:149-56. mektedir. Karın ağrısı, üst gastrointestinal kanama ve peteşial döküntülü hastalarda akla gelmelidir. Tipik endoskopik bulgular tanının konulmasında yardımcı olur, kortikosteroid tedavisi semptomların ve kanamanın kontrolünde faydalıdır.

9. Ueo T, Nakase H, Chiba T. Clinical challenges and images in GI. Unique gastrointestinal involvement in a patient with Henoch-Schonlein purpura. Gastroenterology 2007;133:1076, 1395.

10. Zhang Y, Huang X. Gastrointestinal involvement in Henoch-Schönlein purpura. Scand J Gastroenterol 2008;43:1038-43.

11. Chen MJ, Wang TE, Chang WH, et al. Endoscopic findings in a patient with Henoch-Schonlein purpura. World J Gastroenterol 2005;11:23546.

12. Sharma A, Wanchu A, Kalra N, et al. Successful treatment of severe gastrointestinal involvement in adult-onset Henoch-Schonlein purpura. Singapore Med J 2007;48:1047-50.

13. Ronkainen J, Koskimies O, Ala-Houhala M, et al. Early prednisone therapy in Henoch-Schönlein purpura: a randomized, double-blind, placebo-controlled trial. J Pediatr 2006;149:241-7.

14. Pavlović M, Radlović N, Leković Z, et al. Corticosteroid therapy in Henoch-Schönlein gastritis. [Article in Serbian]. Srp Arh Celok Lek 2007; 135:208-11.

15. Chen MJ, Chang WH, Chu CH, et al. Rapid response of Henoch-Schönlein purpura to corticosteroids: correlation between skin and gastric mucosal lesions. Dig Dis Sci 2007;52:1706-8.

16. Farah R, Shay M. Gastrointestinal involvement in Henoch-Schönlein purpura. Minerva Gastroenterol Dietol 2007;53:295-9. 